\title{
Overweight and Fasting Hyperglycemia in Children Born Preterm in a Resource-Limited Country (Cameroon)
}

\author{
Mah Evelyn Mungyeh1,2, Ngwanou Dany Hermann1, Ngo Um Sap Suzanne',3, Maguip Linda1, \\ Chelo David1,3, Temgoua Ngou Mazou1, Zantia Gides', Chiabi Andréas 1,2, \\ Angwafo III Fru Forbushi1,2
}

\author{
${ }^{1}$ Faculty of Medicine and Biomedical Sciences, The University of Yaoundé, Yaounde, Cameroon \\ ${ }^{2}$ Yaoundé Gyneco-Obstetrics and Pediatrics Hospital, Yaounde, Cameroon \\ ${ }^{3}$ Mother and Child Center, Chantal Biya Foundation, Yaounde, Cameroon \\ Email: aminevelyn@yahoo.co.uk
}

How to cite this paper: Mungyeh, M.E., Hermann, N.D., Suzanne, N.U.S., Linda, M., David, C., Mazou, T.N., Gides, Z., Andréas, C. and Fru Forbushi III, A. (2020) Overweight and Fasting Hyperglycemia in Children Born Preterm in a Resource-Limited Country (Cameroon). Open Journal of Pediatrics, 10, 666-677.

https://doi.org/10.4236/ojped.2020.104069

Received: October 1, 2020

Accepted: December 1, 2020

Published: December 4, 2020

Copyright $\odot 2020$ by author(s) and Scientific Research Publishing Inc. This work is licensed under the Creative Commons Attribution International License (CC BY 4.0).

http://creativecommons.org/licenses/by/4.0/ (c) (i) Open Access

\begin{abstract}
Introduction: The survival of more preterm babies through improved management techniques may imply an increased risk of non-communicable diseases including obesity, diabetes and other cardiovascular risk diseases with age. The prevalence of these diseases varies worldwide. The main objective of this study was to determine the rates and factors associated with overweight and diabetes in children born preterm at the Yaoundé Gyneco-Obstetrics and Pediatrics Hospital. Methodology: We conducted a retrospective cohort study including children aged 6 to 11 years. Data were collected from the records of premature and full-term infants hospitalized from January 1, 2008 to December 31, 2013. Patients were evaluated during outpatient consultation, where height, weight, Body mass index and blood pressure were measured together with fasting capillary blood glucose levels. The Fisher test and the Chi-square test were used to compare proportions. Relative risk (RR) was used to establish the relationship between the different variables. Results: We enrolled 125 children born preterm and 250 born at full-term. The mean age was $8.2 \pm 1.6$ years. The cumulative incidence of pathologies varied according to type: Overweight $32 \%$ in preterm versus $13.6 \%$ in full-term ( $\mathrm{p}=0.00002)$ and $2.4 \%$ with obesity, fasting hyperglycemia $73.20 \%$ in preterm versus $48 \%$ in full-term $(\mathrm{p}<0.001)$. No cases of diabetes were registered. No factors were significantly associated with the occurrence of these diseases in our series. However, there was a positive correlation between obesity and high blood pressure $(\mathrm{r}=1.14, \mathrm{p}=0.000002)$. Conclusion: Overweight was more common in children born preterm than those born full-term. No cases of diabetes were found but there was a significant incidence of pre-diabetic state.
\end{abstract}




\section{Keywords}

Overweight, Diabetes, Prematurity, Low-Income Country

\section{Introduction}

Prematurity, a major public health problem is the second leading cause of neonatal mortality in developing countries. In combination with intrauterine growth retardation, prematurity is now an indicator of the general health status of newborns, and a determinant key of child survival, health and development [1]. In some Western countries, the frequency of prematurity varies from $5 \%$ to 9\% [2] while in Africa, it is estimated to be above 15\% [3] [4]. In Cameroon, the premature birth rate was $13 \%$ in 2010 [5]. At the Yaoundé Gynaeco-Obstetric and Paediatric Hospital in 2011, 26.5\% of newborns admitted to the neonatology unit were premature [6]. The newborn, regardless of birth weight and/or gestational age, is a fragile being. This fragility increases when birth occurs before term, with the potentially serious consequences in the short, medium and long term. Advances in perinatal medicine and neonatology have improved the survival of premature infants. Despite the benefits of these advances in terms of reducing mortality, premature infants are at risk of developing chronic non-communicable diseases in the long term, including obesity and diabetes, increasing subsequent cardiovascular risk [7] [8] [9]. Diabetes in children is more frequent today around the world, due to an improvement in diagnostic techniques and an increase level of knowledge on the mechanism of the onset of this disease. Many studies demonstrated the relationship between prematurity and endocrine disorders such as obesity and diabetes [7]-[13]. The frequency of these diseases is increasing in Europe and Asia, but not systematically assessed in our context. This could explain the scarcity of data on the subject in sub-Saharan Africa in general and Cameroon in particular. The main objective of this study was to determine the factors associated with the occurrence of obesity and diabetes in premature infants. This study will provide data on the extent of the problem in our context together with the associated risk factors; in order to raise attention of health personnel to look out for these diseases during the follow up of premature infants and the early management of detected cases, thus contributing to the reduction of preventable morbidity and mortality in adulthood.

\section{Materials and Methods}

We conducted a historical cohort study over a 6-year period from January 2008 to December 2013; including patients aged 6 - 11 years by June 2019. Were included all newborns regardless of gender and Gestational age, admitted to the neonatal unit during the study period and discharged alive. The exposure factor considered was prematurity. Thus two groups were constituted: children born prematurely and children born at full-term and admitted immediately after their 
respective premature and matched for age and sex. We excluded all small for gestational age, congenital malformations and incomplete records. The minimum sample size was 122 patients, using the formula for cohort study proposed by Charan and Biswas in 2013

$$
\text { Sample size }=\frac{\left[Z_{\alpha} \sqrt{\left(1+\frac{1}{m}\right) p^{*}}\left(1-p^{*}\right)+Z_{\beta} \sqrt{p_{1}}\left(1-p_{1}\right) / m+p_{2}\left(1-p_{2}\right)\right]^{2}}{\left(p_{1}-p_{2}\right)^{2}}
$$

As part of the procedure, after obtaining the research authorizations requested from the competent authorities, we went through the neonatal admission registers where we listed the names of the patients to be included in the study. Then we searched for files and incomplete files or files that did not have a telephone number at this stage were excluded. The parents were then contacted by phone to take appointments for a consultation. After obtaining the informed consent of the parents, the consultation was done, during which parameters such as the height, weight, and abdominal circumference were taken; the right arm Blood pressure was taken after at least 5-minutes rest (three times). Concomitantly, fasting capillary blood glucose levels was performed. Patients with high blood pressure were reviewed 15 days after for re-assessment. Normal cases continued the usual follow-up according to a schedule proposed to them and pathological cases were referred to the appropriate specialist for optimal follow-up.

Diabetes was defined as a fasting capillary blood glucose $>1.26 \mathrm{~g} / \mathrm{l}$ while fasting hyperglycemia was defined as fasting capillary blood glucose was between 1.1 - $1.26 \mathrm{~g} / \mathrm{l}$. Obesity was define as a BMI/age > 3z-score. We defined pre-high blood pressure as a blood pressure between $90^{\text {th }}-95^{\text {th }}$ percentile of blood pressure according to the sex, height and age after three measurements. High blood pressure was defined as blood pressure greater than $95^{\text {th }}$ percentile.

The data were analyzed with the Epi-Info ${ }^{\infty}$ software version 3.5.4. For the comparison of the means in the different groups, the Annova test was used when the distribution was symmetric and the Kruskal Wallis test when it was not. The relative risk (RR) with its 95\% confidence interval was used to establish the strength of the association between the different variables. The Pearson correlation test was used to assess the positive or negative correlation between two quantitative variables. The $\mathrm{p}$ value was calculated by the Fisher test when the number of variables was less than 5 and the Chi-square test was used in the other cases to compare the proportions. The significance threshold was defined for $\mathrm{p}<$ 0.05 .

\section{Ethical considerations}

The ethical clearances of the Institutional Ethics and Research Committee of the Faculty of Medicine of the University of Yaoundé 1 and the Gynaeco-Obstetrics and Paediatric Hospital of Yaoundé were obtained before the start of the study. The data collected were kept strictly confidential and used only for the purposes of the study. 


\section{Results}

We enrolled 125 children born preterm and 250 term born patients matched by age and gender.

\subsection{Sociodemographic Data}

The mean age of premature infants was $8.2 \pm 1.6$ years with extremes of $6-11$ years. There was a slight female predominance, with a sex ratio of 0.98 . The exposed and non-exposed children were comparable for age $(\mathrm{p}=0.98)$ and sex ( $\mathrm{p}$ $=0.6)$. The mean age of the mothers was $28.38 \pm 6.32$ with extremes ranging from 17 to 43 years. The majority was single, primiparous and employed (Table $1)$.

\subsection{Neonatal Profile of the Children}

Most of the preterm children (60\%) were born at a gestational age above 32 weeks, and $65.6 \%$ had birth weight between 1000 and 2000 g. The mean gestational age of exposed children was $33.26 \pm 2.18$ with extremes ranging from 28 and 36 weeks, and an average birth weight of $1940 \mathrm{~g} \pm 456$ (Table 2). The main

Table 1. Distribution by maternal socio-demographic data.

\begin{tabular}{|c|c|c|}
\hline Variables & $\begin{array}{c}\text { Preterm infants }(\mathrm{n}=125) \\
\text { Number }(\%)\end{array}$ & $\begin{array}{c}\text { Term born }(\mathrm{n}=250) \\
\text { Number }(\%)\end{array}$ \\
\hline \multicolumn{3}{|l|}{ Age } \\
\hline$<20$ years & $16(12.80)$ & $24(9.60)$ \\
\hline 20 - 40 years & $105(84.0)$ & $219(87.60)$ \\
\hline$>40$ years old & $4(3.20)$ & $7(2.80)$ \\
\hline \multicolumn{3}{|l|}{ Marital status } \\
\hline Married & $50(40.0)$ & $97(38.80)$ \\
\hline Single & $73(58.40)$ & $153(61.20)$ \\
\hline Divorced & $2(1.60)$ & $0(0)$ \\
\hline \multicolumn{3}{|l|}{ Profession } \\
\hline Employment & $53(42.40)$ & $99(39.60)$ \\
\hline Unemployed & $47(37.60)$ & $84(33.60)$ \\
\hline Student & $25(20.0)$ & $67(26.80)$ \\
\hline \multicolumn{3}{|l|}{ Level of education } \\
\hline Not in school & $1(0.80)$ & $0(0)$ \\
\hline Primary school & $11(8.80)$ & $17(6.80)$ \\
\hline Secondary school & $69(55.20)$ & $126(50.40)$ \\
\hline Superior & $44(35.20)$ & $107(42.80)$ \\
\hline \multicolumn{3}{|l|}{ Parity } \\
\hline Primiparous & $54(43.20)$ & $130(52.0)$ \\
\hline Pauciparous & $43(34.40)$ & $67(26.80)$ \\
\hline Multiparous & $28(22.40)$ & $53(21.20)$ \\
\hline
\end{tabular}


Table 2. Distribution of the population by birth history.

\begin{tabular}{|c|c|c|}
\hline Variables & $\begin{array}{c}\text { Preterm infants }(\mathrm{N}=125) \\
\mathrm{n}(\%)\end{array}$ & $\begin{array}{c}\text { Term born }(\mathrm{N}=250) \\
\mathrm{n}(\%)\end{array}$ \\
\hline \multicolumn{3}{|l|}{ Mode of delivery } \\
\hline Low track & $78(62.40)$ & $143(57.20)$ \\
\hline Caesarean section & $47(37.60)$ & $107(42.80)$ \\
\hline \multicolumn{3}{|l|}{ Place of delivery } \\
\hline$H G O P Y$ & $91(72.80)$ & $167(66.80)$ \\
\hline Other hospitals & $34(27.20)$ & $83(33.20)$ \\
\hline \multicolumn{3}{|l|}{ Gestational age } \\
\hline$<28 S A$ & $1(0.80)$ & - \\
\hline $28-32 S A$ & $50(40.0)$ & - \\
\hline$>32 S A$ & $74(59.20)$ & $250(100)$ \\
\hline Resuscitation at birth & $29(23.20)$ & $46(18.40)$ \\
\hline \multicolumn{3}{|l|}{ Birth weight in grams } \\
\hline$<1000$ & $3(2.40)$ & - \\
\hline $1000-2000$ & $82(65.60)$ & - \\
\hline$>2000$ & $40(32.0)$ & $250(100)$ \\
\hline
\end{tabular}

problems presented by the study population were, neonatal bacterial infections (104 exposed versus 148 unexposed) and neonatal asphyxia (8 exposed versus 28 unexposed). The median length of hospitalization was 9.5 (4 - 15), with extremes ranging from 1 to 45 days. Treatment received during hospitalization was mainly antibiotics, including aminosides (99 exposed versus 129 unexposed), with a median duration of antibiotics of 8 days $(3-10)$ and extremes ranging from 3 to 19 days. The mean duration of use of aminoside was 7 days. Four premature infants were transfused during the hospital stay.

\subsection{The Measured Parameters}

Mean height at follow-up: $136.12 \mathrm{~cm} \pm 14.37 \mathrm{~cm}$ with extremes ranging from $108 \mathrm{~cm}$ to $150 \mathrm{~cm}$. The children had an average weight of $33.28 \mathrm{Kg} \pm 8.28 \mathrm{Kg}$ with extremes ranging from 19 to $61 \mathrm{Kg}$. The mean BMI was $17.99 \mathrm{Kg} / \mathrm{m}^{2} \pm 3.24$ $\mathrm{Kg} / \mathrm{m}^{2}$ with extremes ranging from 10.71 to $29.59 \mathrm{Kg} / \mathrm{m}^{2}$. Overweight was found in $40(32 \%)$ children born preterm against $20(8.0 \%)$ in children born at term. Fasting hyperglycemia was found in $91(72.80 \%)$ preterm children against 68 (27.2\%) in controls (Table 3).

\subsection{Incidence of the Different Pathologies in the Two Study Populations}

We found no cases of diabetes. Patients had hypertension as co-morbidity in $17.60 \%$ of cases (Table 4). Overall, these pathologies were found mainly in former premature infants. 
Table 3. Parameters measured in the study.

\begin{tabular}{|c|c|c|}
\hline Parameters & $\begin{array}{c}\text { Preterm infants }(\mathrm{N}=125) \\
\mathrm{n}(\%)\end{array}$ & $\begin{array}{c}\text { Born at term }(\mathrm{N}=250) \\
\mathrm{n}(\%)\end{array}$ \\
\hline \multicolumn{3}{|c|}{ Abdominal Circumference } \\
\hline$<50 \mathrm{~cm}$ & $2(1.60)$ & $12(4.80)$ \\
\hline$\geq 50 \mathrm{~cm}$ & $123(98.40)$ & $238(95.20)$ \\
\hline \multicolumn{3}{|l|}{ Fasting blood glucose } \\
\hline$<110 \mathrm{mg} / \mathrm{dl}$ & $34(27.20)$ & $182(72.80)$ \\
\hline $110-<126 \mathrm{mg} / \mathrm{dl}$ & $91(72.80)$ & $68(27.20)$ \\
\hline \multicolumn{3}{|c|}{ Systolic Blood Pressure } \\
\hline$<90$ th percentile & $53(42.40)$ & $39(15.60)$ \\
\hline$>90$ th percentile & $72(47.60)$ & $211(84.40)$ \\
\hline \multicolumn{3}{|c|}{ Diastolic Blood Pressure } \\
\hline$<90$ th percentile & $86(68.80)$ & $227(90.80)$ \\
\hline$>90$ th percentile & $39(31.20)$ & $23(9.20)$ \\
\hline \multicolumn{3}{|l|}{ BMI/age (Z-Score) } \\
\hline$>3$ & $3(2.40)$ & $0(0)$ \\
\hline$>2$ & $37(29.60)$ & $20(8.0)$ \\
\hline Between -2 and 2 & $81(64.80)$ & $225(90.0)$ \\
\hline$<-2$ & $3(3.40)$ & $5(2.0)$ \\
\hline$<-3$ & $1(0.80)$ & (0) \\
\hline
\end{tabular}

Table 4. Distribution of pathologies in the two groups.

\begin{tabular}{cccc}
\hline & $\begin{array}{c}\text { Preterm infants } \\
\mathbf{N}=\mathbf{1 2 5} \\
\mathbf{n}(\%)\end{array}$ & $\begin{array}{c}\text { Term born } \\
\mathbf{N}=\mathbf{2 5 0} \\
\mathbf{n}(\%)\end{array}$ & p-Value \\
\hline Fasting hyperglycemia & $91(72.80)$ & $68(27.20)$ & $\mathrm{p}<0.001$ \\
Overweight & $40(32)$ & $20(8.0)$ & $\mathrm{p}=0.00002$ \\
High blood pressure & $22(17.60)$ & $5(2.00)$ & $\mathrm{p}<0.001$ \\
\hline
\end{tabular}

There was a strong correlation between the increase in body mass index and increase in systolic blood pressure, as well as with diastolic blood pressure with a Pearson correlation coefficient of 1.41 (Figure 1 and Figure 2).

\subsection{Factors Associated with Obesity and Diabetes}

The use of aminoglycosides and blood transfusion were associated with the occurrence of fasting hyperglycemia and overweight (Table 5), but did not remain statistically significant after the logistic regression. Therefore, prematurity alone could explain the high incidence of these diseases in the studied population. 


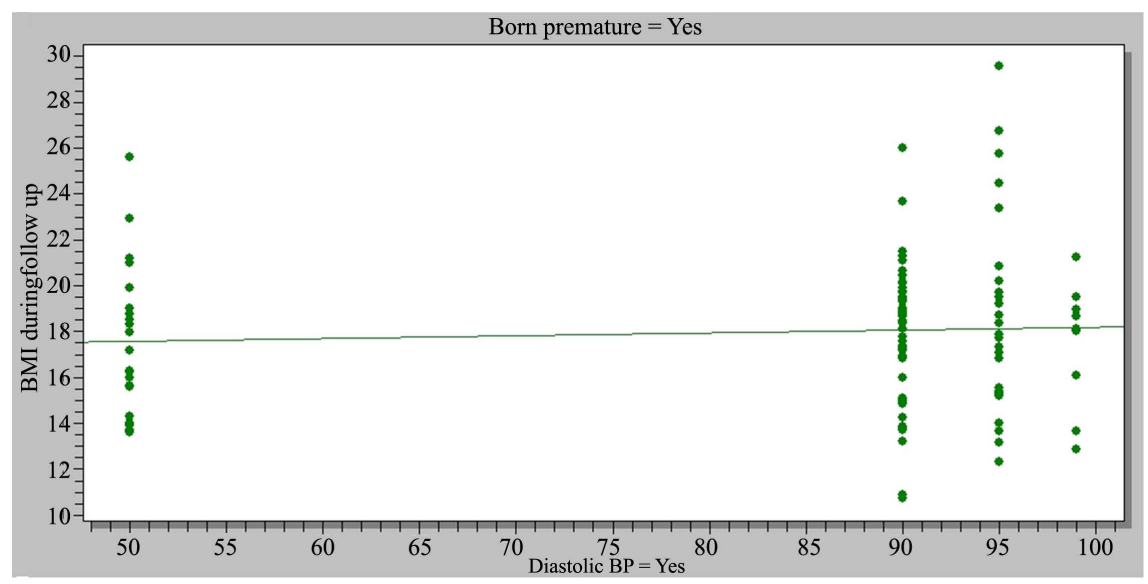

Figure 1. Correlation between BMI and diastolic Blood pressure.

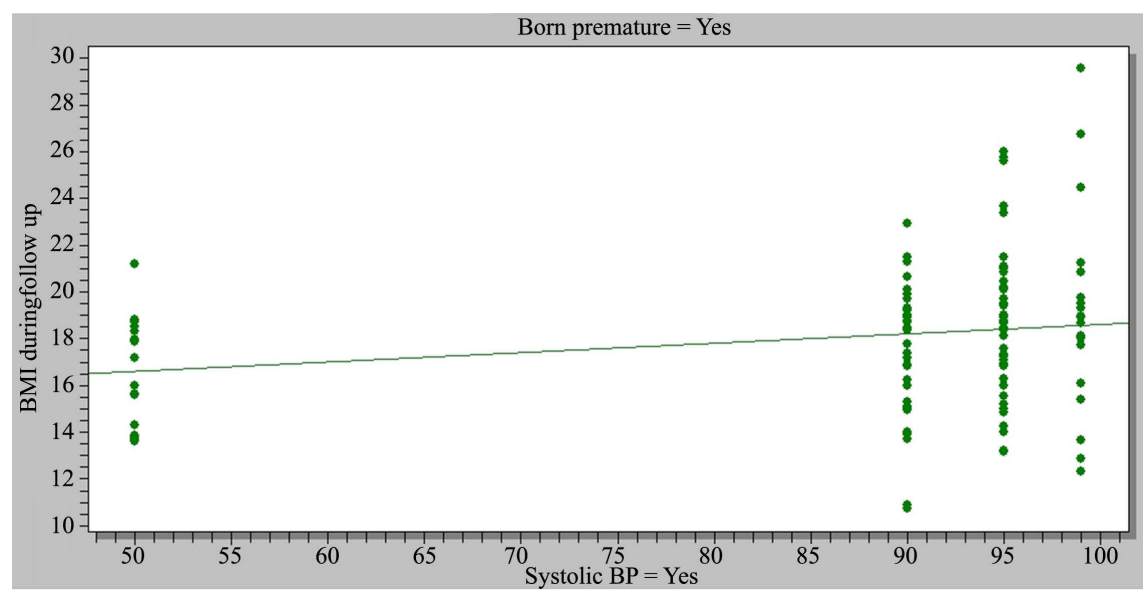

Figure 2. Correlation between BMI and systolic blood pressure.

Table 5. Treatment associated with overweight and fasting hyperglycemia.

\begin{tabular}{|c|c|c|c|c|c|c|}
\hline \multirow{2}{*}{ Variables (treatment) } & \multicolumn{3}{|c|}{$\begin{array}{l}\text { Preterm Infants }(\mathrm{N}=125) \\
\text { Fasting hyperglycemia/overweight }\end{array}$} & \multicolumn{3}{|c|}{$\begin{array}{l}\text { Term born }(\mathrm{N}=250) \\
\text { Fasting hyperglycemia/overweight }\end{array}$} \\
\hline & $\begin{array}{c}\text { Yes } \\
\text { n (\%) }\end{array}$ & $\begin{array}{c}\text { No } \\
\mathrm{n}(\%)\end{array}$ & $\mathrm{p}$ & $\begin{array}{c}\text { Yes } \\
\mathrm{n}(\%)\end{array}$ & $\begin{array}{c}\text { No } \\
\mathrm{n}(\%)\end{array}$ & $\mathrm{p}$ \\
\hline $\begin{array}{l}\text { Aminophylline } \\
\text { Yes/No }\end{array}$ & $28(46.7) / 32(53.3)$ & $35(53.8) / 30(46.2)$ & 0.42 & - & - & - \\
\hline $\begin{array}{c}\text { Blood Transfusion } \\
\text { Yes/No }\end{array}$ & $4(7.7) / 48(92.3)$ & $0(0) / 60(100)$ & 0.04 & $2(1.2) / 165(98.8)$ & $0(0) / 61(100)$ & 0,53 \\
\hline $\begin{array}{c}\text { Umbilical catheter } \\
\text { Yes/No }\end{array}$ & $13(21.7) / 47(78.3)$ & $16(24.6) / 49(75.4)$ & 0.69 & $1(0.5) / 182(99.5)$ & $0(0) / 67(100)$ & 0.36 \\
\hline $\begin{array}{l}\text { Oxygen } \\
\text { Yes/No }\end{array}$ & $9(15) / 51(85)$ & $11(16.9) / 54(83.1)$ & 0.76 & $8(4.4) / 175(95.6)$ & $2(3) / 65(97)$ & 0.62 \\
\hline $\begin{array}{l}\text { AntiH2 } \\
\text { Yes/No }\end{array}$ & $22(36.7) / 38(63.3)$ & $26(40) / 39(60)$ & 0.7 & $10(5.5) / 173(94.5)$ & $3(4.5) / 64(95.5)$ & 0.52 \\
\hline $\begin{array}{l}\text { Aminosides } \\
\text { Yes/No }\end{array}$ & $52(86.7) / 8(13.3)$ & $47(72.3) / 18(27.7)$ & 0.04 & $95(51.9) / 88(48.1)$ & $31(46.3) / 36(53.7)$ & 0.43 \\
\hline
\end{tabular}

${ }^{*}$ Note that only the treatment received during hospitalization had some factors associated with those diseases on the bivariate analysis. 


\section{Discussion}

Of the 125 patients enrolled in our series, 63 were female, giving a slight female predominance with a sex ratio of 0.98 . The average age was 8.2 years with extremes ranging from 6 to 11 years. These findings are different from those of Kaze in Cameroon in 2017 and Grancher in France in 2014 [15] [16] who found a clear predominance of the male sex.

The mothers had an average age of 28.38 years, had mainly a secondary level of education, were mostly primiparous and single. High Blood pressure was the main maternal pathology associated with prematurity. These findings are similar to those of Grancher et al. in France who had also found primiparity, an average age of 29.5 years and hypertension as the main associated pathology to prematurity [16]. Bowers et al., on the other hand, found that a higher level of education was associated with prematurity.

Most of the patients (60\%) were born at a gestational age above 32 weeks, and 65.6\% had birth weight between 1000 and $2000 \mathrm{~g}$. These findings are similar to those of Grancher et al. in 2014 in France in terms of weight but different for gestational age. In fact they found that the majority of children in their series were born between 28 and 32 weeks of gestation. This difference could be explained by the higher mortality of premature babies born before 30 weeks of gestation in our context [6] [15].

In our series, we had no cases of diabetes. On the other hand, we had 91 (72.80\%) children born preterm with fasting hyperglycemia, reflecting a pre-diabetic condition. These results are different from those of the other authors in the literature [8] [9] [10] [11] who found diabetes in their series. Crump et al. found that gestational age at birth was inversely associated with both type 1 and type 2 diabetes risks, and the risk increased with age. However, they stated that this association was only partially explained by shared genetic or environmental factors in families. This difference could be explained by the relatively longer time to assess the occurrence of diabetes in children born preterm, than ours. In fact, in our study we evaluated children aged 6 to 11 years old while the other studies evaluated the risk of diabetes in children aged 15 years and over. We can also justify this difference by the high morbidity and mortality of very premature babies in our context, who are also the most at risk of developing diabetes. Since the onset of diabetes is multifactorial, prematurity alone cannot explain it, but remains a clearly identified risk factor in many studies [9] [10] [11] [15] [16].

Fasting hyperglycemia in our series was influenced by blood transfusion and aminoglycoside use, but these could only be confounding factors. Prematurity alone would explain this fasting hyperglycemia. Many theories have been put forward to explain this: Preterm birth interrupts the development of pancreatic beta cells, which are formed predominantly in the third trimester of pregnancy, and might permanently reduce their number or function [17]. Other contributing factors may include exposure to antenatal corticosteroids and rapid catch-up growth in infancy, leading to visceral adiposity and insulin resistance [18]. 
Therefore, close monitoring of these patients must be done in order to detect and manage diabetes in a timely manner. The other authors also found that factors associated with the onset of diabetes in premature infants included low birth weight, a history of maternal and/or family diabetes, and excess postnatal growth [7] [8] [10] [11]. However, the rate of postnatal growth was not accessed in our series.

Weight gain in preterm infants is used as an indicator of growth and a criterion for hospital discharge [19]. Some studies have reported that "catch-up growth" and weight gain in preterm infants during the critical postnatal period is associated with better cognitive outcomes [20]. However, other studies have reported that nutritional supplements that accelerate catch-up growth increase the risk of future obesity and lead to metabolic syndrome [21]. Environmental influences may also lead to obesity and metabolic syndrome via epigenetic programming in preterm infants. Overweight was found in 40 (32\%) children born preterm compared to $20(8 \%)$ in the control group. Specifically, we had 37 (29.6\%) cases of overweight and $3(2.4 \%)$ cases of obesity among premature children. There was no gender difference. These findings correlate with those of the other authors [7] in the literature, including Tetyana et al. in 2013 in the USA, who had found an increase in the occurrence of obesity with age and prevalence ranging from $22 \%$ to $37 \%$ with age [10]. Ou-Yang et al. reported that preterm infants had a greater likelihood of childhood obesity than term infants. However, no difference of childhood obesity was found between "small for gestational age" (SGA) and "appropriate for gestational age" (AGA) among preterms and that accelerated weight gain also significantly increased the likelihood of subsequent childhood obesity among preterms [22]. We did not find any factors associated with obesity on prematurity in our series. Prematurity, probably eating habits and other risk factors for overweight/obesity could be associated with the occurrence of overweight found in our study. These findings are different from those found by Tetanya et al., who found that preterm children born large for gestational age and increased gestational age were risk factors for later obesity [10]. Prematurity alone cannot explain the onset of obesity, which is known to be multifactorial.

We found a strong positive association between increased body mass index and high systolic blood pressure $(\mathrm{r}=1.14, \mathrm{p}=0.000002)$, as well as a weaker association with high diastolic blood pressure $(\mathrm{r}=0.87, \mathrm{p}=0.001725)$. These findings are similar to those of Bower et al. who reported that postnatal weight gain was positively associated with hypertension [23]. On the other hand Bonamy et al. found that high blood pressure was associated with low gestational age and high body mass index [24]. While Vashishta et al. found that low birth weight and young age at follow up was associated with a higher risk of systolic/diastolic blood pressure $>90^{\text {th }}$ percentile [25]. Barker earlier reported that small fetuses with large placenta were are greater risk of developing high blood pressure in adulthood [26]. They further explained that such discordance could lead to circulatory adaptation in fetus, altered arterial structure in the child and hyperten- 
sion in adulthood.

\section{Limitation of the study}

The major limitation of this study was the short study period. If we had had a longer period, we could have had some cases of diabetes.

\section{Conclusion}

Fasting hyperglycemia, which is a pre-diabetic condition, as well as overweight, was more common in children born preterm. Strict compliance with post-hospital follow-up of premature infants, as well as systematic screening by healthcare professionals is proceeded during routine monitoring of premature infants in order to detect these pathologies early and reduce avoidable morbidity in adulthood.

\section{Acknowledgements}

Hospitals authorities, all collaborators to this project.

\section{Funding}

Private.

\section{Conflicts of Interest}

The authors do not declare any conflict of interest in relation to this article.

\section{References}

[1] Buitendijk, S., Zeitlin, J., Cuttini, M., Langhoff-Roos, J. and Bottu, J. (2003) Indicators of Fetal and Infant Health Outcomes. European Journal of Obstetrics, Gynecology, and Reproductive Biology, 111, S66-S77. https://doi.org/10.1016/j.ejogrb.2003.09.007

[2] Slattery, M. and Morrison, J. (2002) Preterm Delivery. Lancet, 360, 1489-1497. https://doi.org/10.1016/S0140-6736(02)11476-0

[3] Balaka, B., Baeta, S., Agbèrè, A., Boko, K., Kessie, K. and Assimadi, K. (2002) Facteurs de Risque Associés à la Prématurité au CHU de Lomé, Togo. Bulletin de la Société de Pathologie Exotique, 95, 280-283.

[4] Ye, D., Kam, K., Sanou, I., Traore, A., Dao, L. and Koueta, F. (1999) Étude Épidémiologique et Évolutive de la Prématurité dans l'unité de Néonatologie du Centre Hospitalier National-YO de Ouagadougou (Burkina Faso). Annales de Pédiatrie, 46, 643-649.

[5] Howson, C.P., Kinney, M.V. and Lawn, J.E. (2012) Born Too Soon: The Global Action Report on Preterm Birth. World Health Organization, Geneva.

[6] Chiabi, A., Mah, E., Mvondo, N., Nguefack, S., Mbuagbaw, L. and Kamga, K. (2013) Risk Factors for Premature Births: A Cross-Sectional Analysis of Hospital Records in a Cameroonian Health Facility. African Journal of Reproductive, 17, 77-83.

[7] Paz Levy, D., Sheiner, E., Wainstock, T., Sergienko, R., Landau, D. and Walfisch, A. (2017) Evidence That Children Born at Early Term (37-38 6/7 Weeks) Are at Increased Risk for Diabetes and Obesity-Related Disorders. The American Journal of Obstetrics and Gynecology, 217, 588.e1-588.e11.

https://doi.org/10.1016/j.ajog.2017.07.015 
[8] Kajantie, E., Osmond, C., Barker, D. and Eriksson, J. (2010) Preterm Birth-A Risk Factor for Type 2 Diabetes? The Helsinki Birth Cohort Study. Diabetes Care, 33, 2623-2625. https://doi.org/10.2337/dc10-0912

[9] Crump, C., Sundquist, J. and Sundquist, K. (2020) Preterm Birth and Risk of Type 1 and Type 2 Diabetes: A National Cohort Study. Diabetologia, 63, 508-518. https://doi.org/10.1007/s00125-019-05044-z

[10] Vasylyeva, T.L., Barche, A., Chennasamudram, S.P., Sheehan, C., Singh, R. and Okogbo, M.E. (2013) Obesity in Prematurely Born Children and Adolescents: Follow Up in Pediatric Clinic. Nutrition Journal, 12, 150.

[11] Wei, J.-N., Sung, F.-C., Li, C.-Y., Chang, C.-H., Lin, R.-S., Lin, C.-C., Chiang, C.-C. and Chuang, L.-M. (2003) Low Birth Weight and High Birth Weight Infants Are Both at an Increased Risk to Have Type 2 Diabetes Among Schoolchildren in Taiwan. Diabetes Care, 26, 343-348. https://doi.org/10.2337/diacare.26.2.343

[12] Li, S., Zhang, M., Tian, H., Liu, Z., Yin, X. and Xi, B. (2014) Preterm Birth and Risk of Type 1 and Type 2 Diabetes: Systematic Review and Meta-Analysis: Preterm Birth and Diabetes. Obesity Reviews, 15, 804-811.

[13] Kerkhof, G., Breukhoven, P., Leunissen, R., Willemsen, R. and Hokken-Koelega, A. (2012) Does Preterm Birth Influence Cardiovascular Risk in Early Adulthood? The Journal of Pediatrics, 161, 390-396. https://doi.org/10.1016/j.jpeds.2012.03.048

[14] Jaykaran, C. and Tamoghnam, B. (2013) How to Calculate Sample Size for Different Study Designs in Medical Research? Indian Journal of Psychological Medicine, 35, 121-126.

[15] Kaze, F., Itoua, M., Chelo, D. and Halle, M. (2018) Effets de la Prématurité et du Petit Poids de Naissance sur la Pression Artérielle, la Protéinurie et le Débit de Filtration Glomérulaire chez les Enfants de 2 à 5 ans. Néphrologie \& Thérapeutique, $1,335-402$.

[16] Noémie, G. (2013) Evaluation de la Tension Artérielle à l'âge de deux ans des Prématurés de Moins de 33 Semaines d'Aménorrhée au CHU de ROUEN. Médecine Humaine et Pathologie, dumas-00915174.

[17] Crump, C., Sundquist, J., Sundquist, K., et al. (2011) Gestational Age at Birth and Mortality in Young Adulthood. JAMA, 306, 1233-1240.

https://doi.org/10.1001/jama.2011.1331

[18] Kajantie, E., Strang-Karlsson, S., Hovi, P., Wehkalampi, K., Lahti, J., Kaseva, N., Järvenpää, A.-L., Räikkönen, K., Eriksson, J.G. and Andersson, S. (2015) Insulin Sensitivity and Secretory Response in Adults Born Preterm: The Helsinki Study of Very Low Birth Weight Adults. The Journal of Clinical Endocrinology \& Metabolism, 100, 244-250. https://doi.org/10.1210/jc.2014-3184

[19] Kumar, R.K., Singhal, A., Vaidya, U., Banerjee, S., Anwar, F. and Rao, S. (2017) Optimizing Nutrition in Preterm Low Birth Weight Infants-Consensus Summary. Frontiers in Nutrition, 4, 20. https://doi.org/10.3389/fnut.2017.00020

[20] Brandt, I., Sticker, E.J. and Lentze, M.J. (2003) Catch-Up Growth of Head Circumference of Very Low Birth Weight, Small for Gestational Age Preterm Infants and Mental Development to Adulthood. The Journal of Pediatrics, 142, 463-470. https://doi.org/10.1067/mpd.2003.149

[21] Embleton, N.D., Korada, M., Wood, C.L., Pearce, M.S., Swamy, R. and Cheetham, T.D. (2016) Catch-Up Growth and Metabolic Outcomes in Adolescents Born Preterm. Archives of Disease in Childhood, 101, 1026-1031. https://doi.org/10.1136/archdischild-2015-310190 
[22] Ou-Yang, M.C., Sun, Y., Liebowitz, M., Chen, C.C., Fang, M.L., et al. (2020) Accelerated Weight Gain, Prematurity, and the Risk of Childhood Obesity: A Meta-Analysis and Systematic Review. PLoS ONE, 15, e0232238.

https://doi.org/10.1371/journal.pone.0232238

[23] Bowers, K., Liu, G., Wang, P., Ye, T., Tian, Z., Liu, E., et al. (2011) Birth Weight, Postnatal Weight Change, and Risk for High Blood Pressure among Chinese Children. Pediatrics, 127, e1272-e1279. https://doi.org/10.1542/peds.2010-2213

[24] Bonamy, A., Kallen, K. and Norman, M. (2012) High Blood Pressure in 2.5 Yars Old Children Born Extremely Preterm. Pediatrics, 129, e1199-e1204. https://doi.org/10.1542/peds.2011-3177

[25] Vashishta, N., Surapaneni, V., Chawla, S., Kapur, G. and Natarajan, G. (2017) Association among Prematurity ( $<30$ Weeks' Gestational Age), Blood Pressure, Urinary Albumin, Calcium, and Phosphate in Early Childhood. Pediatric Nephrology, 32, 1243-1250. https://doi.org/10.1007/s00467-017-3581-Z

[26] Barker, D.J.P., Bull, A.R., Osmond, C. and Simmonds, S.J. (1990) Fetal and Placental Size and Risk of Hypertension in Adult Life. British Medical Journal, 301, 259-262. https://doi.org/10.1136/bmj.301.6746.259 